\title{
Atatürk Havalimanı Verileri Kullanılarak Rayleigh Dağılım Yöntemiyle İstanbul'un Rüzgâr Karakteristiğinin Tahmini
}

\author{
Sertaç GÖRGÜLÜ ${ }^{1 *}$ \\ ${ }^{1}$ Burdur Mehmet Akif Ersoy Üniversitesi, Mühendislik - Mimarlık Fakültesi, Elektrik - Elektronik Mühendisliği Bölümü, Burdur, Türkiye (ORCID: 0000-0002-8394- \\ 5362) \\ (İlk Geliş Tarihi 9 Ağustos 2019 ve Kabul Tarihi 1 Eylül 2019)
}

(DOI: $10.31590 /$ ejosat.604739)

\begin{abstract}
ATIF/REFERENCE: Görgülü, S. (2019). Atatürk Havalimanı Verileri Kullanılarak Rayleigh Dağılım Yöntemiyle İstanbul'un Rüzgâr Karakteristiğinin Tahmini. Avrupa Bilim ve Teknoloji Dergisi, (17), 103-108.
\end{abstract}

\section{$\ddot{\mathbf{O z}}$}

Nüfus artışı ve sanayileşme ile birlikte gelişen teknoloji elektrik enerjisine olan talebi gün geçtikçe arttırmaktadır. Elektrik enerjisi ise yoğun olarak çevreye olan zararlarıyla ön plana çıkan ve tükenmekte olan fosil yakıt kaynakları kullanılarak üretilmektedir. Fosil yakıt kaynaklarının bu olumsuz etkilerinden dolayı yenilenebilir enerji kaynaklarından elektrik üretimine olan talep hızla artmaktadır. Ayrıca, enerji ithalatçısı olan ülkeler dışa bağımlılıklarını azaltmak için yerli ve yenilenebilir enerji kaynaklarına yönelmektedir. Elektrik enerjisi üretiminde kullanılan en önemli yenilenebilir enerji kaynaklarından birisi de rüzgâr enerjisidir. Rüzgârın sürekli olmaması, hızının değişken olması, kontrol edilemiyor olması gibi nedenler, rüzgâr santrali yatırımlarının gerçekleştirilmesi için çeşitli yöntemler kullanılarak fizibilite çalışmalarının yapılmasını gerekli kılmaktadır. Rüzgâr enerjisi potansiyelini belirlemede kullanılan çeşitli yöntemler vardır. Bu yöntemlerden biri de Rayleigh dağılım fonksiyonudur. Rayleigh dağılım fonksiyonu belirli bir bölgenin rüzgâr enerjisi potansiyelini belirlemede kullanılan istatistiksel yöntemlerden birisidir. Rüzgâr enerji potansiyeli ile ilgili olarak Türkiye'nin farklı bölgeleri için çeşitli çalışmalar yapılmıştır. Bu çalışmada ise, Atatürk Havalimanı meteoroloji istasyonundan alınan veriler yardımıyla İstanbul için ortalama rüzgâr hızı frekans yoğunluğu ve rüzgâr gücü yoğunluğu Rayleigh dağılım fonksiyonu kullanılarak belirlenmiştir. 1 Kasım 2015 - 31 Ekim 2017 tarihleri arasındaki iki yıllık verilerin kullanıldığı bu çalışmada İstanbul ili için rüzgâr potansiyeli tahmini yapılmıştır. Meteoroloji istasyonundan alınan rüzgâr hızı verileri yardımıyla yapılan tahminler ve gerçek değerler ile Rayleigh dağılım fonksiyonundan elde edilen bu tahmini değerler karşılaştırılmıştır. Rayleigh dağılımının, olasılık yoğunluk tahmininde 0.877 korelasyon katsayısı ile güç yoğunluğunda ise \%11.5 ile kabul edilebilir mertebede sonuçlar verdiği görülmüştür. Elde edilen bu sonuçlara göre bölgede rüzgâr enerjisi santrali kurulumuna uygun bir potansiyel bulunmadığı tespit edilmiştir.

Anahtar Kelimeler: Meteorolojik veri, Rayleigh dağılımı, Rüzgâr tahmini.

\section{Estimation of Istanbul's Wind Characteristics via Rayleigh Distribution Method by Using Ataturk Airport Data}

\begin{abstract}
Population growth and technological advancements with industrialisation continuously increase the demand for electricity. Electricity is heavily produced with fossil fuel sources, which are environmentally hazardous and wasting assets. Due to the negative effects of using fossil fuels, the need for electricity production by renewable energy sources increase rapidly. Additionally, energy importing countries tend to national and renewable energy to decrease their external dependence. One of the most important renewable energy sources using in electricity production is wind energy. Due to the discontinuous wind, shifting wind speed and its uncontrollable nature, wind plant investments require various feasibility studies beforehand. There are multiple methods to determine the potential of wind power, one of which is Rayleigh distribution functions. Rayleigh distribution is a statistical method to determine a region's wind energy
\end{abstract}

\footnotetext{
* Sorumlu Yazar: Burdur Mehmet Akif Ersoy Üniversitesi, Mühendislik - Mimarlık Fakültesi, Elektrik - Elektronik Mühendisliği Bölümü, Burdur, Türkiye, ORCID: 0000-0002-8394-5362, sgorgulu@mehmetakif.edu.tr
} 
potential. There are a number of studies on the wind energy potential of Turkey's different regions This study calculates the average wind speed frequency and wind power density for Istanbul with Rayleigh distribution, using the data from Istanbul Ataturk Airport meteorological station. By analysing two years of data from 01 November 2015 to 31 October 2017, this study projects the wind power potential for the city of Istanbul. Projections with the help of the wind speed data from the meteorological station are compared to estimations from Rayleigh distributions. The results are found to be acceptable with 0.877 correlation coefficient from the probability density projection and $11.5 \%$ in power density. Accordingly, there is not enough potential in the Istanbul region for a wind power plant installation.

Keywords: Meteorological data, Rayleigh distribution, Wind estimation.

\section{Giriş}

Dünyadaki hızlı nüfus artışıyla beraber endüstriyel gelişim ve refah seviyesindeki artış, enerjiye olan talep artışını beraberinde getirmektedir (Eren vd., 2016; Demir Yetiş vd., 2019). Gün geçtikçe artan bu talebi karşılamak için fosil yakıtlar yoğun olarak kullanılmaktadır. Dünya enerji arzında büyük paya sahip olan fosil yakıt kaynaklarının kullanılması hem atmosfere yüksek oranda insan kaynaklı sera gazlarının (karbondioksit, metan, diazot monoksit, vb.) salınımına neden olmakta hem de fosil yakıt kaynaklarının rezervlerinin hızlı bir şekilde tükenmesine ve dolayısıyla fiyat dalgalanmalarına neden olmaktadır. Bu durum enerjide dışa bağımlı olan ülkelerin ekonomisinde önemli problemlere neden olmaktadır. Enerjide dışa bağımlılığı azaltmak için dünya çapında yenilenebilir enerjilere yönelim artmıştır (Kurnuç Seyhan ve Badem, 2018; Fidan ve Alkan, 2014). Bu çerçeveden bakıldığında yenilenebilir enerji kaynaklarının önemi daha net bir şekilde ortaya çıkmaktadır. Yenilenebilir enerji kaynaklarının fosil yakıtlara göre daha temiz, daha güvenilir ve daha ekonomik olduğu bilinmektedir (Kılıç ve Urgun, 2016). Fosil enerji kaynaklarının oluşturduğu problemlerin azaltılması amacıyla bilim adamları yeni enerji üretim araçları üzerine odaklanmış ve özelikle enerji üretimi ve dönüştürülmesi sırasında çevresel sorunlara neden olmayıp temiz enerji kaynağı olmaları sebebiyle yenilenebilir enerji kaynaklarına yönelmiştir (Şenel ve Koç, 2015)

Rüzgâr enerjisi en önemli yenilenebilir enerji kaynaklarından birisidir ve güneş radyasyonunun yeryüzündeki alanları farklı 1sıtmasından kaynaklanır. Yüzeylerin farklı ısınması, hava sıcaklığında, basınçta ve nemde farklılıklar olmasına ve bu farklar da havanın hareketine ve rüzgâr oluşumuna neden olur. Rüzgâr enerjisi; yenilenebilir olması, atmosferde serbest ve bol miktarda bulunması ve çevre kirliliği oluşturmaması gibi avantajlara sahiptir ve enerji açığının kapatılması için daha fazla faydalanılması gereken bir yenilenebilir enerji kaynağıdır. Dünya ve dünyamıza hayat veren güneş var oldukça var olacak rüzgâr enerjisinden faydalanmak için rüzgârın başka bir enerji şekline dönüştürülmesi gerekmektedir. Bu dönüşüm için rüzgâr türbinleri kullanılmaktadır (Şenel ve Koç, 2015).

Herhangi bir bölgenin rüzgâr enerjisi potansiyelinin analizinin yapılabilmesi için o bölgede rüzgâr yönü ve saatlik rüzgâr hızı bilgilerinin en az bir yıl boyunca ölçülmesi gerekmektedir (Kaplan, 2016). Alınan rüzgâr verileri, teknik ve ekonomik açıdan incelenerek rüzgâr enerjisi santralinin kurulumu için yatırım analizinde kullanılır (Doğanşahin vd., 2019). Son yıllarda Türkiye'de de rüzgâr enerjisi potansiyelinin belirlenmesinde yoğun çalışmalar sürdürülmekte ve bölgesel olarak istatistiksel analizler yapılmaktadır. Çeşitli dağılım parametreleri kullanılarak ve çözüm yöntemlerinden yararlanılarak durum değerlendirmeleri yapılmaktadır. Aynı analizler diğer ülkelerdeki bölgeler için de yapılmakta her ülke yenilenebilir enerji kaynaklarının en etkin şekilde kullanımı için çaba sarf etmektedir. Kamerun'da yapılan bir çalışmada Garoua şehri uluslararası havaalanında meteoroloji tarafından yapılan ölçümler kullanılmış ve şehrin rüzgâr enerjisi potansiyelinin belirlenmesi için iki parametreli Weibull dağılımından yararlanılmıştır. Çalışmada $k$ şekil parametresi ve $c$ ise ölçek parametresi olarak tanımlanmıştır. Parametre tahmininde çözüm yöntemi olarak altı yöntem kullanılmıştır. Bunlar: Ampirik Metodu (EM), Enerji Model Faktörü Metodu (EPF), Grafik Metodu (GM), Maksimum Olabilirlik Metodu (MLM), Moment Metodu (MM) ve Düzeltilmiş Maksimum Olabilirlik Metodu (MMLM)'dur. Yapılan analiz neticesinde şehrin rüzgâr enerjisi potansiyelinin elektrik üretiminde istenilen düzeyde olmadığı ve mevcut rüzgâr enerjisi potansiyelinin tarımsal sulamada ve yel değirmenlerinin çalıştırılmasında daha faydalı olacağı anlaşılmıştır (Kidmo vd., 2015).

Rüzgâr enerjisinden elektrik üretimi ve rüzgâr türbini kurulumu için yer seçimi ile ilgili çalışma yapan Bhattacharya ve Bhattacharjee (2010) iki parametreli Weibull dağılımından yararlanarak rüzgâr enerjisi potansiyeli analizi yapmıştır. Hesaplamalarda Lineer En Küçük Kareler Metodu ve Maksimum Olabilirlik Metodu (MLM) kullanılarak parametreler hesaplanmıştır. Mert ve arkadaşları (2014) Antakya bölgesinin rüzgâr potansiyeli ile ilgili bir çalışma yapmış ve bölgedeki rüzgâr karakteristiğini incelemiştir. Analiz için iki parametreli Weibull dağılımı ve Log-normal dağılımından faydalanılmıştır. Dağılımlarda ortalama rüzgâr hızı ve güç yoğunluğu tahminleri için Maksimum Olabilirlik Metodu (ML) ve En Küçük Kareler Metodu (LSM) kullanılmıştır. Rüzgâr enerjisi potansiyelini belirlemek için yapılan başka bir çalışmada Kaplan (2016) Osmaniye bölgesinin rüzgâr enerjisi potansiyelini analiz etmiş ve analizde Rayleigh ve iki parametreli Weibull dağılımlarından yararlanmıştır. Parametre tahmini yapmak için Grafik ve Moment Metodu kullanılmıştır. Analizler sonucunda Weibull dağılımı için Grafik Metodunun gerçek değerlere daha çok uyum sağlamıştır. Rayleigh dağılımında ise Moment metodu kullanılırsa gerçek verilere daha yakın sonuçlar elde edilebileceği anlaşılmıştır. Yapılan diğer bir çalışmada Menemen'in rüzgâr enerji potansiyelini bulmak için Weibull ve Rayleigh dağılımlarını kullanılmıştır. Çalışmanın sonuçları, bölgenin rüzgâr potansiyelinin elektrik enerjisi üretimi açısından uygun olduğunu göstermiştir (Gülersoy ve Çetin, 2010). Bababurnu, Belen, Datça ve Gökçeada olmak üzere dört farklı bölgenin rüzgâr enerjisi potansiyeli ve güç yoğunluklarının belirlenmesi için yapılan istatistiksel bir analiz çalışmasında Rayleigh ve iki parametreli Weibull dağılımını kullanmıştır (Korukçu, 2011). Türkiye'nin batı, güney ve güneybatı kıyılarında bulunan bazı ilçelerdeki rüzgâr enerjisi potansiyelini istatistiksel olarak analiz edildiği başka bir çalışmada Weibull ve Rayleigh dağılım fonksiyonlarının yanında WAsP (Wind Atlas Analysis and Application Program) programı da kullanılarak analizler yapılmış ve elde edilen değerler ölçülen verilerle karşılaştırılmıştır (Bilgili vd. 2010).

Bu çalışmada, Rayleigh dağılım yöntemi kullanılarak İstanbul şehri için rüzgâr enerjisi potansiyeli araştırılmıştır. 2015 yılının kasım ayı ile 2017 Ekim ayları arası iki yıllık rüzgâr verisi yardımıyla ortalama rüzgâr hızı ve ortalama rüzgâr gücü hesaplanmıştır. 
Ayrıca rüzgâr olasılık fonksiyonu hesaplanmış ve ölçülmüş değerlerle karşılaştırılmıştır. Performans ölçütü olarak seçilen korelasyon katsayısına göre sonuçlar tartışılmıştır.

\section{Dünyada ve Türkiye’de Rüzgâr Enerjisi Kurulu Gücü}

Dünyanın rüzgâr enerjisi kurulu gücü gün geçtikçe artmaktadır. 2017 yllında bir önceki yıla göre \%10.8 artış gösteren dünya kurulu güç kapasitesi 2018 yılında 600 GW'a ulaşmıştır (WWEA, 2019). Şekil 1'de yıllara göre dünyadaki rüzgâr kurulu güç değiş̧imi görülmektedir (WWEA, 2018).

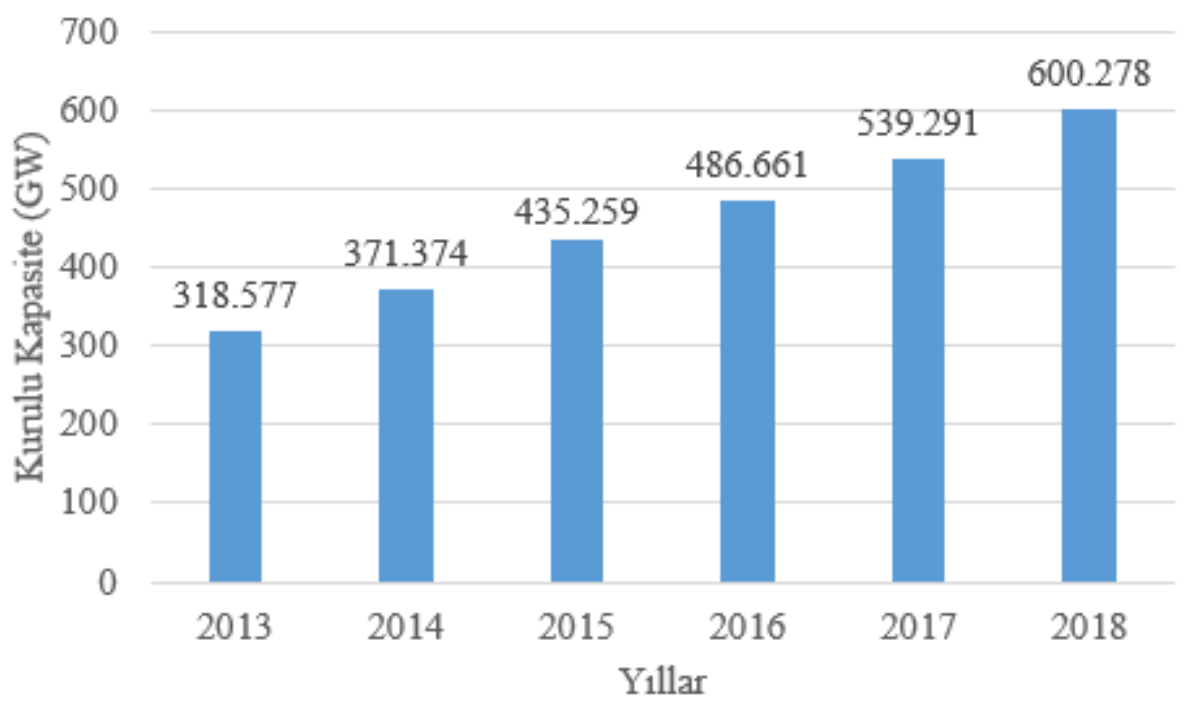

Şekil 1. 2013 - 2018 yllların arasında dünyadaki rüzgâr kurulu gücünün değişimi

Tüm dünyada olduğu gibi ülkemizde de rüzgâr santrallerine olan ilgi gün geçtikçe artmakta ve devlet tarafindan verilen teşvikler de bu artışa hız katmaktadır. Şekil 2'de ülkemizdeki rüzgâr kurulu gücünün yıllara göre değişimi görülmektedir. (TUREB, 2019). Şekilde de görüldüğü üzere 2018 yılında bir önceki yıla göre rüzgâr kurulu gücünde yaklaşık 500 MW'lık bir artış olmuştur. 2018 y1lının ilk yarısı itibariyle ülkemizin kurulu gücü 87139 MW olmuştur (ETKB, 2018). 2018 y1lı itibariyle ülkemizin rüzgâr kurulu gücü toplam kurulu gücün yaklaşık \% 8.5 'ine ulaşmış durumdadır.

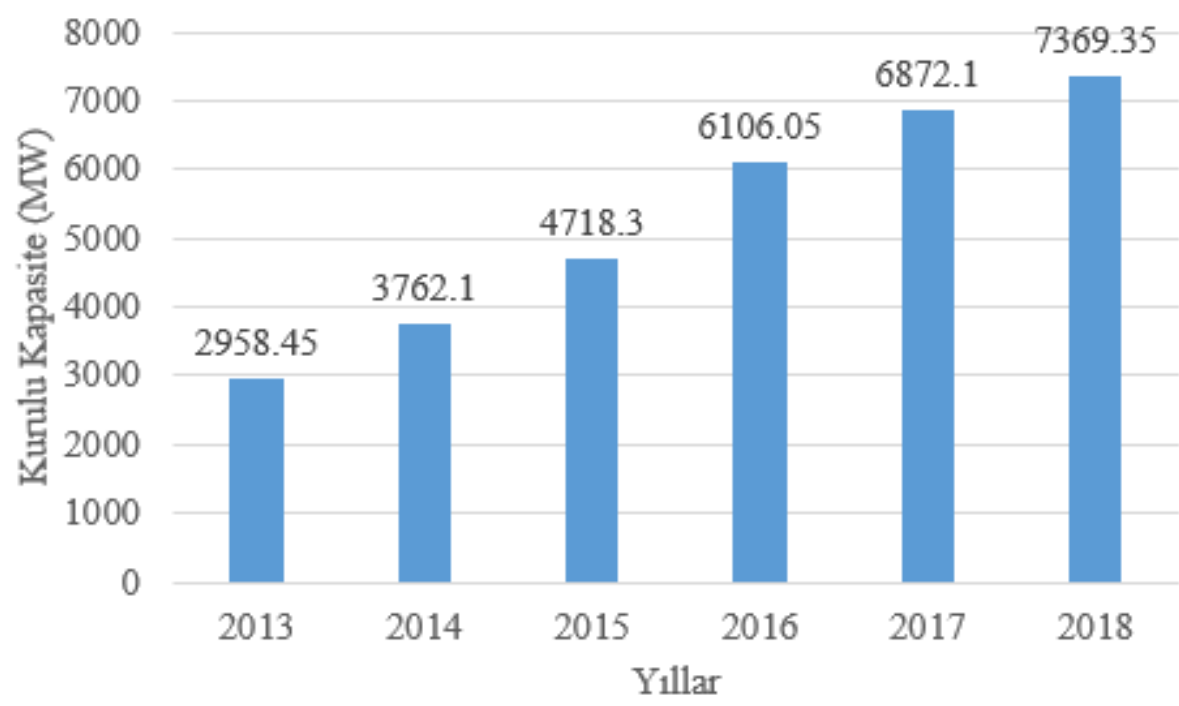

Şekil 2. 2013 - 2018 yllların arasında Türkiye'deki rüzgâr kurulu gücünün değişimi 


\section{Materyal ve Metot}

Belirli bir dönem için ortalama rüzgâr hızının ve rüzgâr gücünün tahmininde birçok yöntem kullanılmaktadır. Bunlardan geleneksel istatistiksel yöntemler en sık kullanılan yöntemlerden biridir. Bu yöntemler arasında da sıklıkla kullanılan yöntemler Weibull, Rayleigh dağılım fonksiyonlarıdır. Bunlardan Rayleigh modeli Weibull modelinin basitleştirilmiş özel bir halidir. Tek parametreli olduğundan Rayleigh dağılımı Weibull dağılımına göre daha az esnektir fakat parametrelerin hesabı daha kolaydır (Kurban vd., 2007). Rayleigh yoğunluk fonksiyonu ve kümülatif dağılım fonksiyonu sırasıyla aşağıdaki formüllerle hesaplanır (Gülersoy ve Çetin, 2010):

$$
\begin{aligned}
& f_{R}(v)=\left(\frac{\pi}{2}\right)\left(\frac{v}{v_{m}^{2}}\right) \exp \left[-\left(\frac{\pi}{4}\right)\left(\frac{v}{v_{m}^{2}}\right)^{k}\right] \\
& F_{R}(v)=1-\exp \left[-\left(\frac{\pi}{4}\right)\left(\frac{v}{v_{m}}\right)^{2}\right]
\end{aligned}
$$

Sadece hız ve hız ortalaması verileri kullanılarak sonuca ulaşılabilmesi Rayleigh modelinin en önemli avantajlarındandır. Rayleigh dağılımının rüzgâr tahminlerinde geçerliliği literatürdeki birçok kaynakta vurgulanmıştır. Rayleigh yönteminde ortalama rüzgâr güç yoğunluğu aşağıdaki bağıntı yardımıyla hesaplanır (Kurban vd., 2007):

$$
P_{R}=\frac{3}{\pi} \rho v_{m}^{3}
$$

Burada $\rho$ havanın yoğunluğu olup İstanbul Atatürk havalimanı için $1.225 \mathrm{~kg} / \mathrm{m}^{3}$ alınabilir. Ölçüm değerleri ile tahmin sonuçlarının kıyaslanmasında kullanılacak performans ölçütü, korelasyon katsayısı $\left(\mathrm{R}^{2}\right)$ olarak belirlenmiştir. Korelasyon katsayısının formülü aşağıdaki gibidir (Kurban vd., 2007):

$$
R^{2}=1-\frac{\sum_{i=1}^{n}\left(y_{i}-x_{i}\right)^{2}}{\sum_{i=1}^{n}\left(y_{i}-y_{m}\right)^{2}}
$$

Eşitlik 4'te $y$ değerleri ölçülmüş değerleri, $x$ değerleri tahmin edilmiş değerleri, $y_{m}$ ise $y$ değerlerinin ortalamasını temsil etmektedir.

\section{Bulgular}

İstanbul şehri için, Meteoroloji Genel Müdürlüğü İstanbul Atatürk Havalimanı ölçüm istasyonundan alınmış olan 1 Kasım 2015 31 Ekim 2017 tarihleri arasındaki iki yıllık saatlik rüzgâr hızı verileri (17481 adet veri) kullanılarak analiz yapılmıştır. Öncelikle bu verinin belirli hız aralıkları için frekanslarının $(f)$, hız ortalamalarının $\left(v_{m}\right)$ ve olasılık yoğunluklarının $\left(f_{R}\right)$ hesaplanması gereklidir. İstanbul şehri için, belirtilen tarihler arasında en yüksek hız $5.8 \mathrm{~m} / \mathrm{s}$ olarak gerçekleşmiş olup, analiz için $1 \mathrm{~m} / \mathrm{s}$ 'lik hız aralıkları kullanılmıştır. Tablo 1'de analiz için gerekli değerler listelenmiştir.

Tablo 1. Ölçülmüş verilerin istatistiksel dă̆glımı

\begin{tabular}{c|c|c|c|c}
\hline $\boldsymbol{i}$ & $\boldsymbol{v}_{\boldsymbol{i}}(\boldsymbol{m} / \mathbf{s})$ & $\boldsymbol{f}_{\boldsymbol{i}}$ & $\boldsymbol{v}_{\boldsymbol{m}, \boldsymbol{i}}(\boldsymbol{m} / \mathbf{s})$ & $\boldsymbol{f}_{\boldsymbol{R}}\left(\boldsymbol{v}_{\boldsymbol{i}}\right)=\frac{\boldsymbol{f}_{\boldsymbol{i}}}{\sum \boldsymbol{f}_{\boldsymbol{i}}}$ \\
\hline 1 & $0-1$ & 3406 & 0.660 & 0.1948 \\
\hline 2 & $1-2$ & 8213 & 1.421 & 0.4698 \\
\hline 3 & $2-3$ & 4977 & 2.331 & 0.2847 \\
\hline 4 & $3-4$ & 777 & 3.272 & 0.0444 \\
\hline 5 & $4-5$ & 96 & 4.286 & 0.0055 \\
\hline 6 & $5-6$ & 12 & 5.167 & 0.0007 \\
\hline
\end{tabular}


European Journal of Science and Technology

Ölçülen gerçek veriler ve Rayleigh dağılımından elde edilen olasılık yoğunluk fonksiyonlarının değişimi Şekil 3’te verilmiştir.

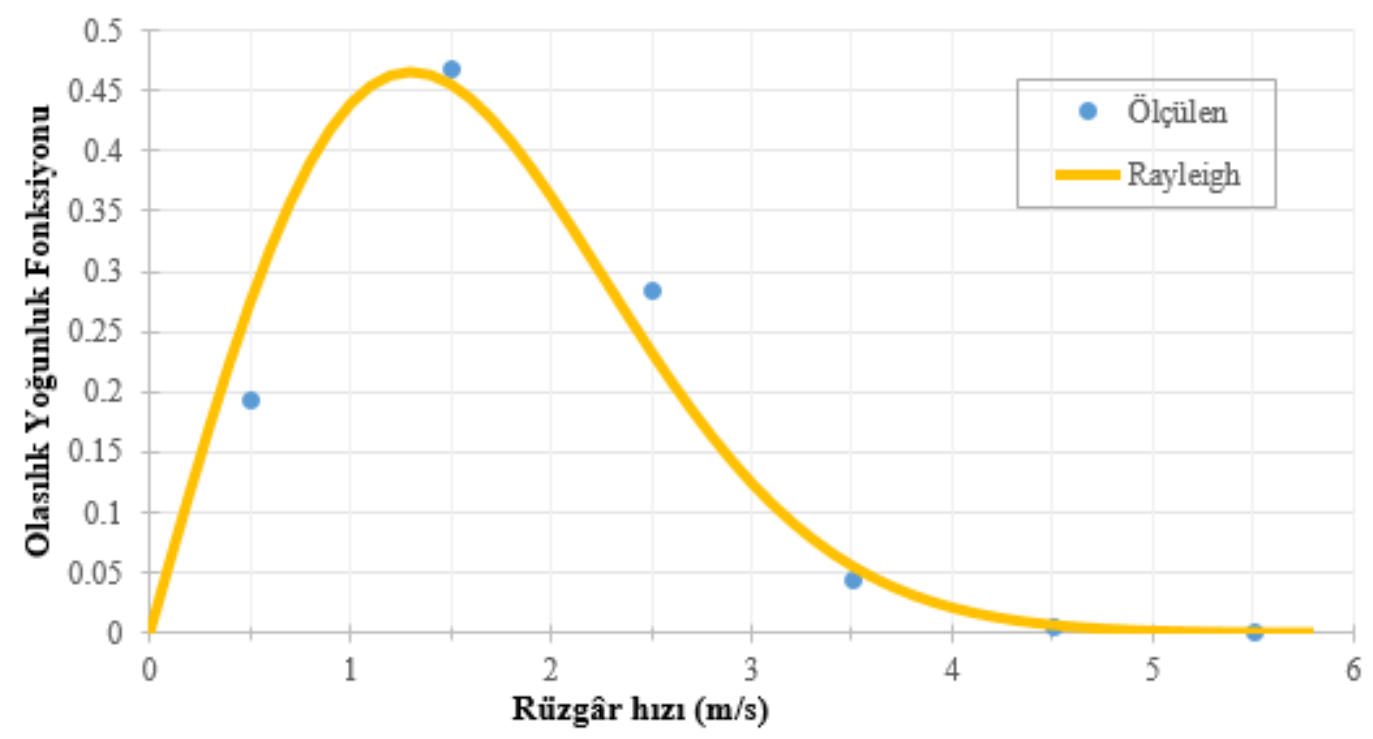

Şekil 3. Olasılık yoğunluk fonksiyonunun rüzgâr hızıyla değişimi

Şekil 3 'te görülebileceği gibi, Rayleigh dağılımından elde edilen sonuçlar gerçek değerlere oldukça yakın çıkmıştır. Hız arttıkça bu yakınsamanın daha da arttığı görülmektedir. Tablo 2'de referans alınan iki yıllık dönem için ortalama hız ve ortalama rüzgâr gücü yoğunluğu ile olasılık yoğunluk fonksiyonuna ait korelasyon katsayısı değerleri verilmiştir. Rayleigh dağılımı hesaplamalarda gerçek ortalama hızı kullandığı için ortalama hızlar aynıdır. Rüzgâr gücü yoğunluğunda ise Rayleigh dağılımı ile bulunan sonuç gerçek durumdan yaklaşık \%11.5 daha büyük çıkmıştır. Olasılık yoğunluk fonksiyonun karşılaştırma ölçütü $\left(R^{2}\right)$ ise Tablo 2'den de görüldügüü gibi 0.877 olarak gerçekleşmiştir.

Tablo 2. Gerçek değerler ile Rayleigh dă̆gllımı sonuçlarının karşılaş̧ırılması

\begin{tabular}{c|c|c}
\hline Parametre & Gerçek & Rayleigh \\
\hline$v_{m}(\mathrm{~m} / \mathrm{s})$ & 1.632 & 1.632 \\
\hline$P_{R}\left(\mathrm{~W} / \mathrm{m}^{2}\right)$ & 4.562 & 5.086 \\
\hline$R^{2}$ & - & 0.877 \\
\hline
\end{tabular}

\section{Sonuç}

Ülkemizin yenilenebilir enerji potansiyelini belirlemek için çeşitli çalışmalar yapılmakta ve potansiyel atlasları oluşturulmaktadır. Enerji güvenliği açısından dışa bağımlılığı azaltmak ve fosil yakıt kaynaklarının olumsuz etkilerini en az seviyeye indirmek bağlamında yenilenebilir enerji kaynaklarına olan yatırımların artması için teşvikler sağlanmaktadır. Bu çalışma ülkemizin potansiyel olarak sahip olduğu yenilenebilir enerji kaynaklarından rüzgâr enerjisi üzerine gerçekleştirilmiştir. Bu çalışmada; Rayleigh dağılım yöntemi kullanılarak İstanbul şehri için olasılık yoğunlukları ve ortalama rüzgâr gücü tahmin edilmiştir. Meteoroloji istasyonundan alınan iki yıllık saatlik rüzgâr hızı verisi yardımıyla tahminler yapılmış ve gerçek değerler ile Rayleigh dağılım fonksiyonundan elde edilen bu tahmini değerler karşıllaştırılmıştır. Rayleigh dağılımının, olasılık yoğunluk tahmininde 0.877 korelasyon katsayısı ile güç yoğunluğunda ise \%11.5 ile kabul edilebilir mertebede sonuçlar verdiği görülmüş̧ür. Analizi yapılan iki yıllık dönem için geçerli olmak kaydıyla, bölgenin çok fazla rüzgâr almadığı, rüzgâr gücünün düşük olduğu tespit edilmiştir. Ancak daha uzun dönemde alınacak veriler ve yapılacak analizler farklı sonuçlar ortaya koyabilir. 


\section{Kaynakça}

Bhattacharya, P., \& Bhattacharjee, R. (2010). A study on Weibull distribution for estimating the parameters. Journal of Applied Quantitative Methods, 5, 234-241.

Bilgili, M., Şahin, B., \& Şimşek E. (2010). Türkiye'nin güney, güneybatı ve batı bölgelerindeki rüzgâr enerjisi potansiyeli. Isı Bilimi ve Tekniği Dergisi, 30, 01-12.

Demir Yetiş, A., Gazigil, L., Yetiş, R., \& Çelikezen, B. (2019). Hayvansal atık kaynaklı biyogaz potansiyeli: Bitlis örneği. Akademik Platform Mühendislik ve Fen Bilimleri Dergisi, 7 (1), 74-78.

Doğanşahin, K., Uslu, A. F., \& Kekezoğlu, B. (2019). İki Bileşenli Weibull Dağılımı ile Rüzgâr Hızı Olasılık Dağılımlarının Modellenmesi. Avrupa Bilim ve Teknoloji Dergisi, (15), 315-326.

Eren, M.V., Atay Polat, M., \& Aydın, H. İ. (2016). Türkiye'de yapısal kırılmalı testlerle elektrik tüketimi ve ekonomik büyüme arasındaki ilişkinin analizi. Akademik Bakış Uluslararası Hakemli Sosyal Bilimler Dergisi, 56, 275-289.

ETKB, (2018). Enerji ve Tabii Kaynaklar Bakanlığı, https://www.enerji.gov.tr/tr-TR/Sayfalar/Elektrik Erişim Tarihi: 12 Aralık 2018.

Fidan, M.S., \& Alkan, E. (2014). Bitkisel Hammaddelerden elde edilen biyodizelin alternatif enerji kaynağı olarak kullanılması. Gümüşhane Üniversitesi Fen Bilimleri Enstitüsü Dergisi, 4 (2), 144-160.

Gülersoy, T., \& Çetin, N.S. (2010). Menemen bölgesinde rüzgâr türbinleri için Rayleigh ve Weibull dağıllımlarının kullanılması. Politeknik Dergisi, 13 (3), 209-213.

Kaplan, Y.A. (2016). Rayleigh ve Weibull dağılımları kullanılarak Osmaniye bölgesinde rüzgâr enerjisinin değerlendirilmesi. Süleyman Demirel Üniversitesi Fen Bilimleri Enstitüsü Dergisi, 20, 62-71.

Kılıç, R., \& Urgun, N. (2016). Türkiye'de yenilenebilir enerji kaynaklarına yönelmenin ülke ekonomisine etkileri ve Türkiye'nin enerjideki dışa bağımlılığının azaltılmasına yönelik katkıları. Dumlupınar Üniversitesi Sosyal Bilimler Dergisi, 47, 148-166.

Kidmo, D.K., Danwe, R., Doka, S.Y., \& Djongyang, N. (2015). Statistical analysis of wind speed distribution based on six Weibull methods for wind power evaluation in Garoua, Cameroon. Revue des Energies Renouvelables, 18, 105-125.

Korukçu, M.Ö. (2011). Türkiye'de dört yerleşim yeri için rüzgâr enerjisi potansiyelinin belirlenmesi. Uludağ Üniversitesi MühendislikMimarlık Fakültesi Dergisi, 16, 117-126.

Kurban, M., Hocaoğlu, F.O., \& Kantar, Y.M. (2007). Rüzgâr enerjisi potansiyelinin tahmininde kullanılan iki farklı istatistiksel dağglımın karşılaştırmalı analizi. Pamukkale Üniversitesi Mühendislik Bilimleri Dergisi, 13 (1), 103-109.

Kurnuç Seyhan, A., \& Badem, A. (2018). Erzincan ilindeki hayvansal atıkların biyogaz potansiyelinin araştırılması. Akademik Platform Mühendislik ve Fen Bilimleri Dergisi, 6 (1), 25-35.

Mert, İ., Karakuş, C., \& Peker, F. (2014). Antakya bölgesi rüzgâr karakteristiğinin incelenmesi. Dicle Üniversitesi Mühendislik Fakültesi Mühendislik Dergisi, 5 (1), 13-22.

Şenel, M.C., \& Koç, E. (2015). Dünya'da ve Türkiye'de rüzgâr enerjisi durumu-genel değerlendirme. Mühendis ve Makina, 56 (663), 46-56.

TUREB, (2019). Türkiye Rüzgar Enerjisi Birliği, Türkiye rüzgar enerjisi istatistik raporu 2019, Ankara, 50p, http://www.tureb.com.tr/files/bilgi_bankasi/turkiye_res_durumu/turkiye_ruzgar_enerjisi_istatistik_raporu_ocak_2019.pdf Erişim Tarihi: 17 Şubat 2019.

WWEA, (2019). World Wind Energy Association, Wind power capacity worldwide reaches $600 \mathrm{GW}, 53,9 \mathrm{GW}$ added in 2018, http://wwindea.org/blog/2019/02/25/wind-power-capacity-worldwide-reaches-600-gw-539-gw-added-in-2018/ Erişim Tarihi: 25 Şubat 2019.

WWEA, (2018). World Wind Energy Association, Half-year statistics 2017, http://wwindea.org/blog/2017/12/20/half-year-statistics2017/ Erişim Tarihi: 21 Aralık 2018. 